\title{
Advanced three-dimensional geomechanical and hydrogeological modelling for a deep open pit
}

\author{
L Cotesta Vale, Canada (formerly Itasca Consulting Canada, Inc.) \\ J Xiang Itasca Denver Inc., USA \\ B Paudel Vale, Canada (formerly Itasca Consulting Canada, Inc.) \\ R Sterrett Itasca Denver Inc., USA \\ J Sjöberg Itasca Consultants $A B$, Sweden \\ T Dilov Ellatzite-Med AD, Bulgaria \\ I Vasilev Ellatzite-Med AD, Bulgaria \\ Z Yalamov Ellatzite-Med $A D$, Bulgaria
}

\begin{abstract}
The Ellatzite open pit mine, located in Bulgaria, is a large copper mine with a current mining depth in excess of $500 \mathrm{~m}$. During the last few years, Ellatzite-Med AD and Itasca International Inc. have jointly conducted a large slope stability analysis project utilising an integrated geomechanical and hydrogeological approach with the overall goal of assessing the stability of the open pit slopes for current and future mining.

The conducted work has included developing a Geomechanical Framework Model to describe the rock mass in quantitative terms. This model is based on extensive data collection from active open pit walls, boreholes, and drainage tunnels, and includes a detailed interpretation of the lithological and structural characteristics of the site. The structural geology of the site is complex, with a large number of lithological contacts and faults, all interpreted as discontinuities with the potential to slip. Hence, a 3D discontinuum approach was required to represent the geomechanical environment in a numerical model for stability assessment. The approach used enabled including all lithological contacts and faults (more than 50 large-scale, undulating, discontinuities) in a mine-scale 3DEC model.

A hydrogeological model was developed in parallel to quantify pore pressure conditions in the rock mass. Faults were also included also in the hydro-model, and calculated pore pressures were then exported to the 3DEC model for stability assessment. Joint fabric, simulated as ubiquitous joints, were also included in the geomechanical model. The model results were compared against observations and deformation measurements from the open pit. Near-future mining scenarios were investigated and various mitigating measures, such as drainage and/or slope geometry alterations were developed. The modelling work is at the forefront of what is possible in discontinuum 3D slope stability analysis of complex structural-geological conditions and for practical open pit stability assessments.
\end{abstract}

Keywords: geomechanical framework model, discontinuum modelling, hydrogeological modelling, 3D slope stability analysis

\section{Introduction}

Ellatzite-Med AD operates the Ellatzite open pit mine, located near the city of Etropole which is about $80 \mathrm{~km}$ east of Sofia in Bulgaria. The mine exploits a low-grade copper/gold porphyry deposit, located below a ridge of ground which is bounded on its east, west, and north sides by incised river valleys. Currently, mining takes place at more than $500 \mathrm{~m}$ depth from the ground surface. Ground conditions are complex, with many lithological units and a large number of large-scale faults, as well as pervasive joint fabric and challenging 
groundwater conditions. With ever-increasing planned pit depths and possible continued mining for many years into the future, pit slope stability remains a crucial issue for the mine. An extensive project on large-scale slope stability assessment was initiated as a joint effort between Ellatzite-Med AD and Itasca International Inc. The project has utilised an integrated geomechanical and hydrogeological approach with the overall objective of assessing the stability of the open pit slopes for current and future mining. The project work has been conducted in several phases from 2013 through 2019.

\section{Geomechanical Framework Model}

At the start of the project, it was apparent that all relevant data had to be combined into an integrated model to enable understanding, querying, and communicating data between the parties involved. To this purpose, a Geomechanical Framework Model (GFM) was developed. A conceptual schematic of a GFM is shown in Figure 1. This also highlights also how the GFM is used to facilitate communication of datasets across a mine design team and to management and stakeholders. The GFM was used to develop understanding of the geomechanical conditions and to provide input to the hydrogeological and geomechanical analyses and modelling conducted as part of the entire study.

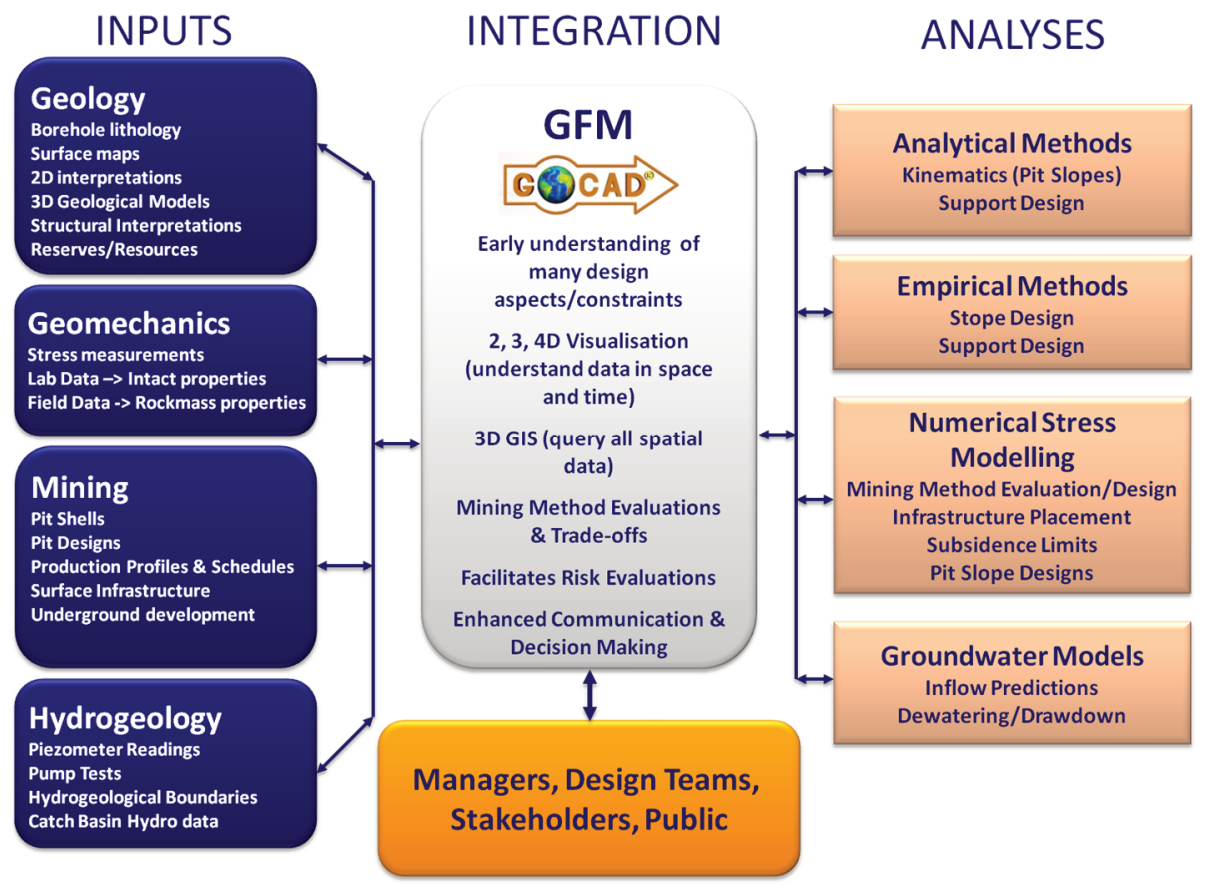

Figure 1 Conceptual schematic of the Geomechanical Framework Model (GFM) for surface and underground mining projects

The following key elements were incorporated into the GFM for Ellatzite:

1. Geological model.

2. Structural model (large-scale faults/structures and small-scale joint fabric).

3. Geomechanical characterisation data.

4. Geomechanical laboratory data.

5. In situ stresses.

6. Pit excavations (historical and future).

The GFM was, in turn, based on data collected in the active open pit, from boreholes and drainage tunnels, etc. At a later stage, pit slope performance was used to validate analyses as part of the full integration. 
As a direct result of this project, the level of geological and geomechanical knowledge of the technical staff onsite has greatly improved. Ellatzite technical staff reinterpreted much of the geological and large-scale structural models for the site during the course of the work. The new geological model for Ellatzite is subdivided into six main lithological units: Grano-diorites, Hornfels, Monzo-Diorites, Schists, Phyllites, and Sandstone. Each of the main lithology groups was further subdivided into structural-litho groups based on the Ellatsi-1(E1) and Ellatsi-2 (E2) faults, resulting in a total of 20 separate domains. The new fault model consisted a total of 59 faults, 20 of which were termed first-order faults and 39 were termed second-order faults (Figure 2). Many faults are coincident with lithological contacts. Moreover, all lithological contacts are discontinuous (versus being healed) and have the same character and behaviour as the faults. Both contacts and faults were treated as discontinuities within the numerical models. Small-scale structural features were also imported into the GFM, including ubiquitous joints (bench-scale $\approx 10-15 \mathrm{~m}$ ), foliation (bench-scale $\approx 10-15 \mathrm{~m}$ ), and master joints and small faults (inter-ramp scale $\approx 30-40 \mathrm{~m}$ ). This information was used to help assess the joint fabric within each of the units that would later be incorporated into the stability models.

Rock mass characterisation included data from 1,138 locations within the pit. For each lithology group, data from the three major classification systems used were incorporated into the GFM: GSI (Marinos \& Hoek 2000), RMR (Bieniawski 1989), and MRMR (Laubscher 1990). The geomechanical data were further analysed using the interpolation techniques within Gocad $^{T M}$ to estimate a property at a given location based on a nearby set of known values. For this, the estimated GSI = RMR-5 (Hoek et al. 1995) was used (Figure 2).

An updated database containing all laboratory testing results for the various rock types spanning years 1996 to 2017 was implemented into the GFM and categorised by each lithology group and the corresponding structural-litho domains. Similar to the rock mass properties, the structural-litho domains do not vary much from the litho domains, except in the case of the Schist unit. The domains located within the southeast region, bounded by the Ellatsi-1 and Ellatsi-2 faults, have lower strength and there are also visual indications of strength degradation in this region. The in situ stress state was assessed based on experience and regional stress trends; no direct measurement data were available. Pit excavation geometries for historical and future pit excavation sequence were developed from historical survey elevation data as well as current mine plans.

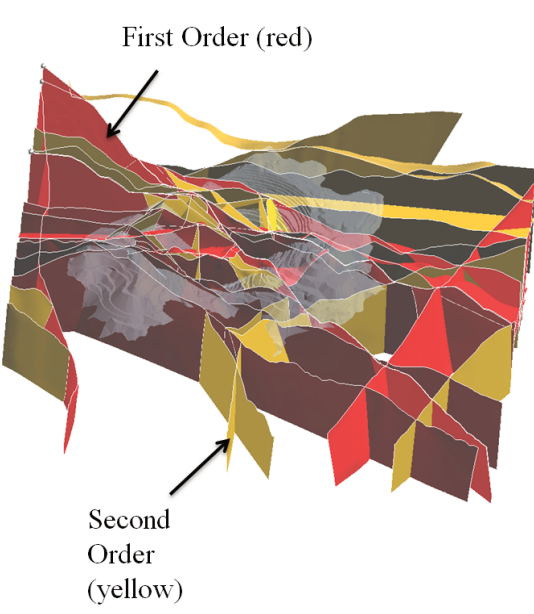

(a)

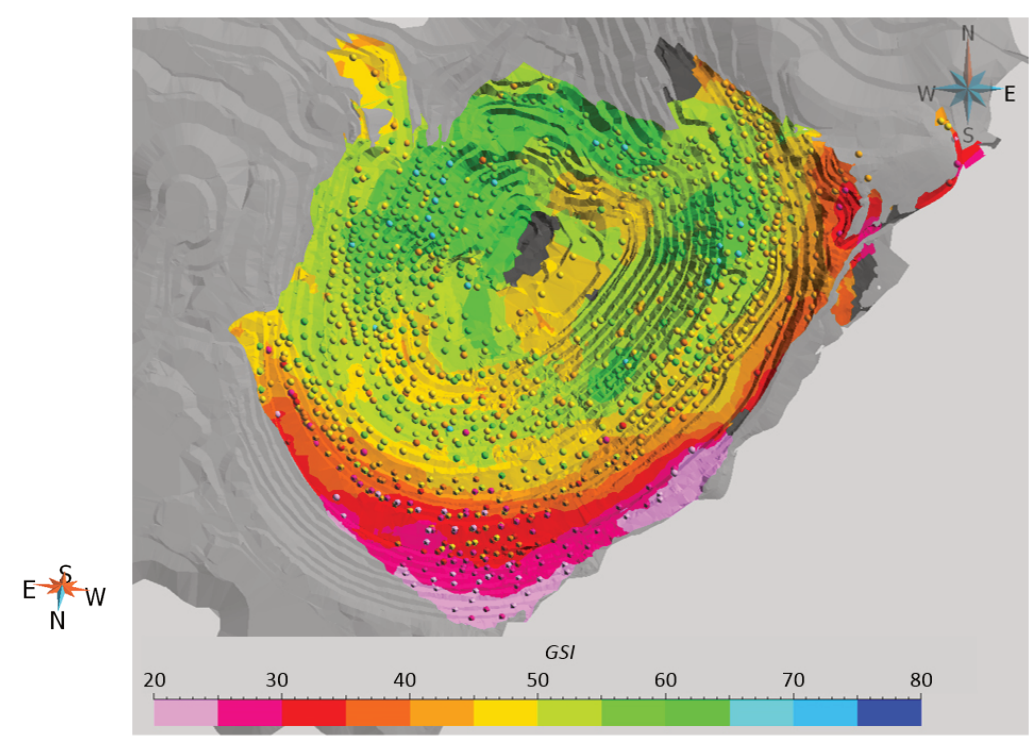

(b)

Figure 2 Examples from the Geomechanical Framework Model: (a) Updated fault model showing first-order (red) and second-order (yellow) faults; (b) Estimated values for GSI (RMR-5) contoured on the 2017 pit topography 


\section{$3 \quad$ Groundwater flow modelling}

A detailed groundwater flow model was constructed with the purpose of simulating past and current hydrogeological conditions at the mine. Then model was then used to simulate the effectiveness of a conceptual future dewatering program in reducing the pore pressures behind the pit slopes. An important part of this was also to provide, as input, pore pressure data to the geomechanical slope stability analyses. The 3D groundwater model was developed using the numerical code MINEDW ${ }^{\mathrm{TM}}$ (Azrag et al. 1998). This code solves 3D groundwater flow problems with an unconfined (or phreatic) surface using the finite-element method, and the code has been used at a wide variety of mining conditions throughout the world. There are three main attributes of MINEDW that are pertinent to the modelling for this study:

1. The simulation of the continuous excavation of a pit in one uninterrupted model run allows the flexibility to provide pore pressure distributions for any given point in time.

2. The propagation of a zone of relaxation (ZOR) based on the mining schedule can be simulated.

3. Predicted pore pressures from the model can be interpolated for use in geomechanical modelling.

The six major hydrogeological units were incorporated into the model-Phyllites, Schists, Hornfels, Porphyries, Granodiorites, and Sandstone. The extents of each unit were based on input from the GFM. Outside of the areal extent covered by the geological maps, the geologic units were extended to the model boundaries based on the trend of each unit. Waste rock piles were identified by checking the topography and then simulated in the model. The geological units in the groundwater model are shown in Figure 3 . The hydraulic properties of the geologic units were based on data in the GFM and refined in model calibration. Most geologic units exposed in the Ellatzite pit are low hydraulic conductivity $(K)$ units, which do not transmit large amounts of water or freely drain. In addition to the lithological units, a total of 12 of the major faults, believed to be the hydraulically most important ones, were incorporated into the model. The major faults were simulated with a small band of finely discretised finite elements. All faults represented in the model are simulated with low $K$ values so that they act as leaky barriers to groundwater flow.

The 3D shape of the pit over time was simulated in the model by nodes with time-variable elevations $(Z)$, using the collapsing grid capability of MINEDW. Excavation of the open pit was simulated with drain nodes (or with zero pore pressure conditions) according to the assumed mining schedule and the pit configurations. Drainage galleries and sub-horizontal drainholes were simulated with drain nodes, which were activated in the model at different times to correspond to when the galleries and drainholes were completed and active. As mining proceeds, a ZOR (developing due to stress release) was simulated by increasing the $K$ value of the in situ rock within the extent of the ZOR.

Pre-mining (steady-state) conditions were simulated to establish baseline groundwater levels. Using the simulated water levels derived from the steady-state simulation as the initial groundwater conditions, transient-model calibration was conducted. The transient-model calibration compared simulated water levels to measured water levels from 35 monitoring wells and 28 piezometers. In general, the model-simulated water levels agreed reasonably well with the measured water levels in the pit area, as exemplified in Figure 4. However, simulated water levels in a few of the piezometers did not correlate well with measured water levels. A possible reason may be an impermeable fault that separates the shallow and deep monitoring wells. However, the model was judged to be sufficiently well calibrated to conduct various conceptual dewatering/depressurisation simulations based on the findings from the geomechanical model simulations. 

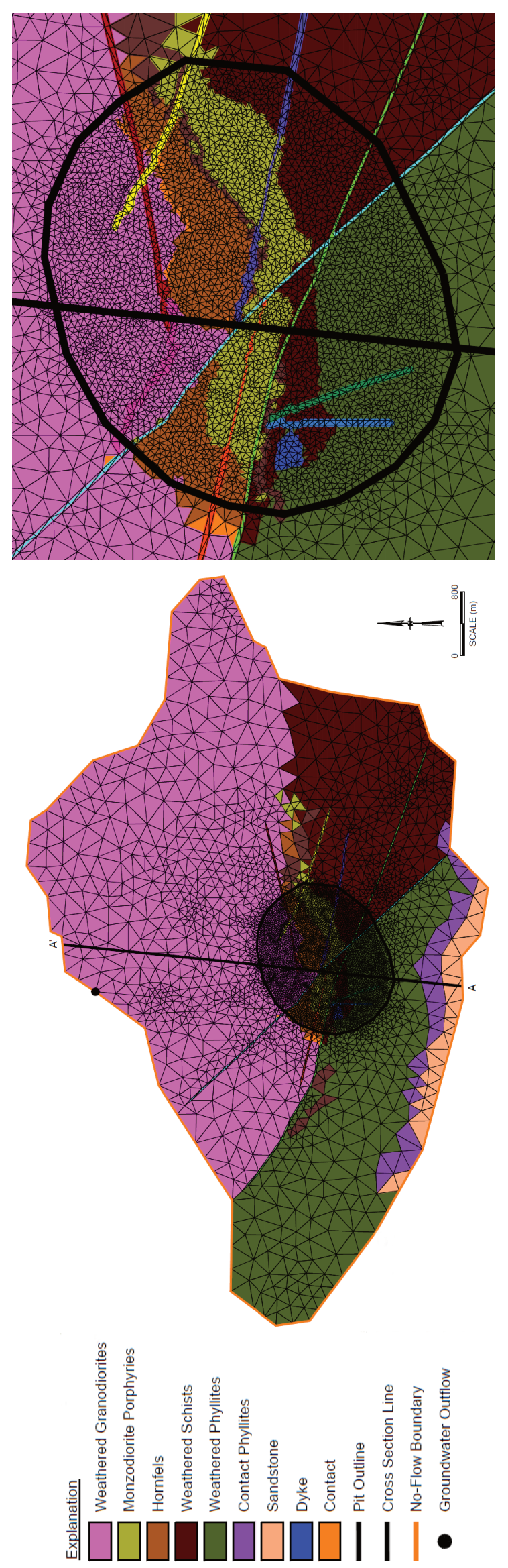
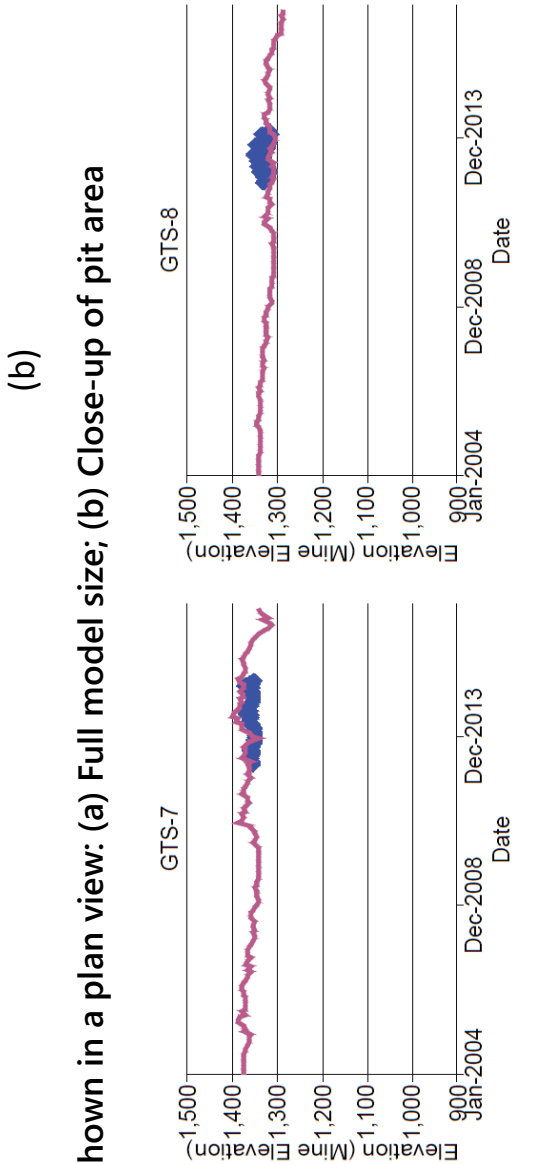

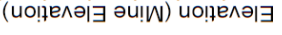
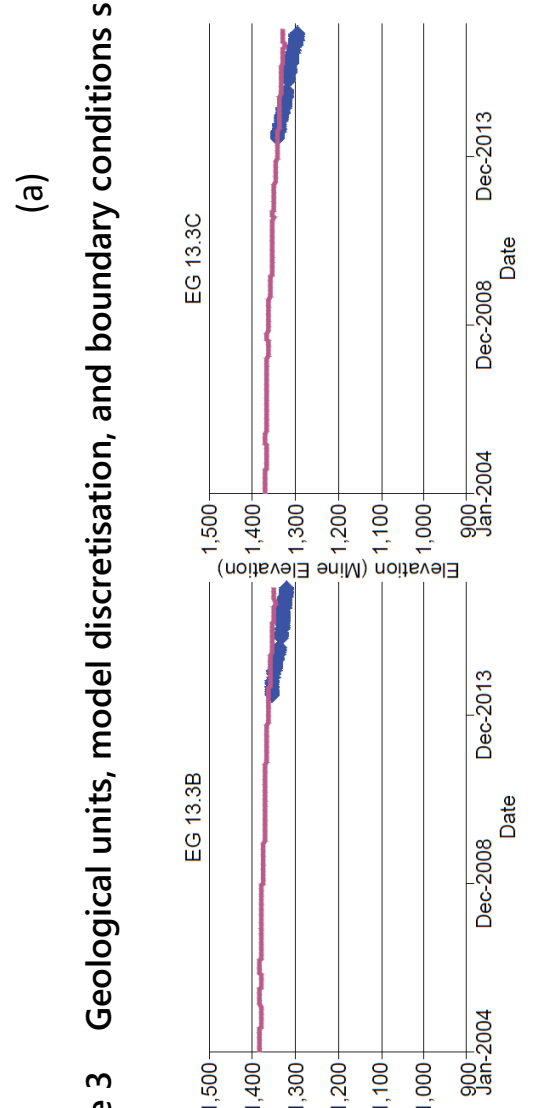

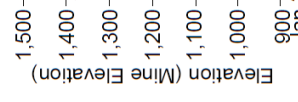

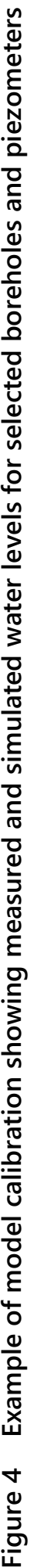




\section{$4 \quad$ Geomechanical modelling}

The geomechanical numerical modelling was conducted in parallel with the groundwater flow modelling to benefit from cross-communication between the two sub-disciplines. The modelling comprised four separate tasks:

1. Local 2D modelling of an instability event in the south wall.

2. Geotechnical berm $2 \mathrm{D}$ analysis.

3. 3D mine-scale model.

4. 3D detailed model of the southeast (SE) deformational event.

The first task enabled calibration of rock mass and joint properties for the weak Phyllite and Schist units. The second task was conducted to provide input to the design of a geotechnical berm suggested as a remedial measure for the potentially unstable areas in the south wall. These tasks are not presented in this paper.

The two 3D-models are presented in more detail below. The mine-scale model was developed to assess stability conditions throughout the open pit and for current as well as future mining. The model was also used as scoping tool for the more detailed 3D model of the SE deformational event. The latter included more detail concerning strength variation and focused on replicating observed historical instabilities.

\subsection{Mine-scale geomechanical numerical model}

A mine-scale 3D discontinuum model in 3DEC (Itasca Consulting Group, Inc. 2018a) was set up to model the entire pit and all geological and structural features. The model included 59 faults, 20 different structural-lithology groups along with their contacts, and waste rock dump materials. The model also incorporated surface topography as well as pit topography for six different excavation stages: years 2015, 2017, 2021, 2023, 2026, and 2031 (Figure 5). The model was constructed using a novel pre-processing approach employing the Griddle (Itasca Consulting Group, Inc. 2018b) meshing tool.
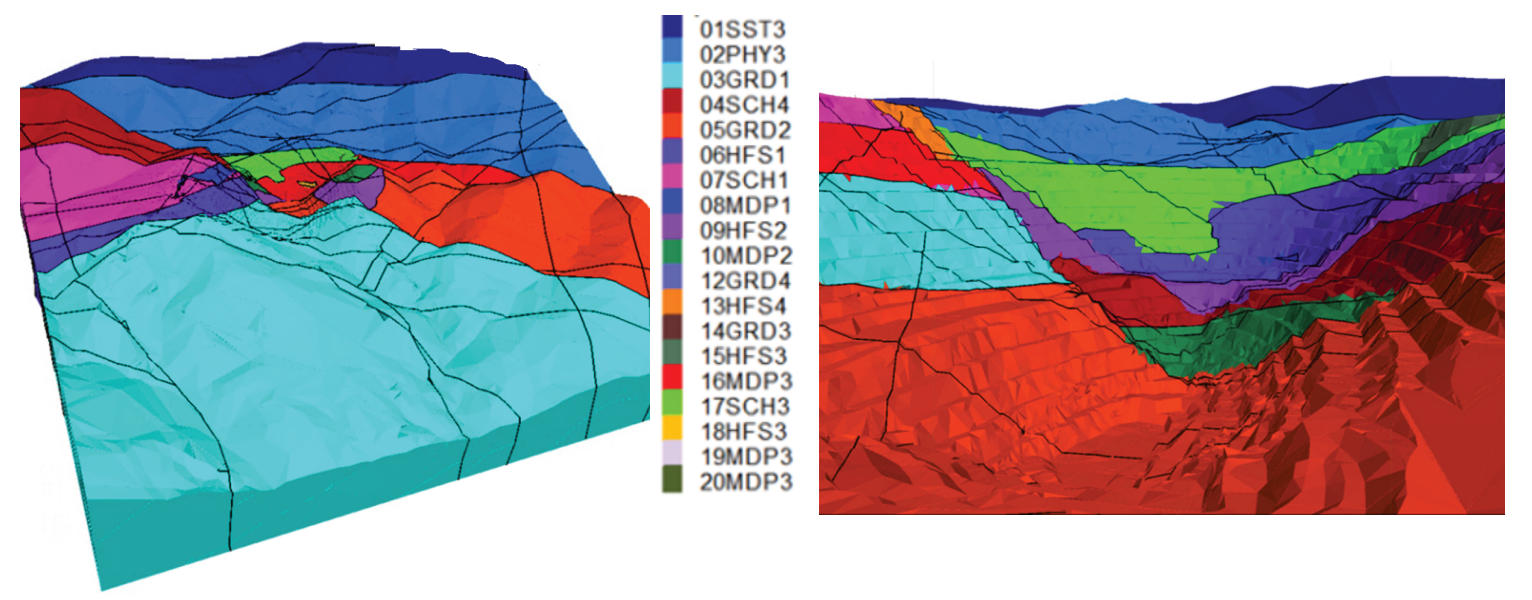

Figure 5 Two views of the 3DEC model showing the lithology groups, contact and faults (as traces), and the detailed bench geometry for a given excavation stage (waste dumps not shown) 
Input data to the 3DEC models were primarily obtained from the GFM, supplemented with experience-based data. In order to consider variability in some of the rock mass parameters and to understand the respective significance for the model response, two main categories of rock mass were analysed: (i) strong rock mass (mean value properties along with a disturbance factor, $D$, of 0.0 ; Hoek et al. 2002), and (ii) weak rock mass (mean value properties along with a disturbance factor of 0.7 ). A bi-linear Mohr-Coulomb constitutive behaviour (elastic-perfectly plastic) was considered for the rock-matrix. For the waste rock dump materials, because of the low strength, a linear Mohr-Coulomb constitutive behaviour was applied. Faults were modelled with a Coulomb slip failure criterion. Orientations of the foliations on the pit wall surfaces were considered in the form of ubiquitous joints.

Starting from a single material model, complexities were gradually added by introducing more rock materials, followed by the introduction of faults. Once the results obtained from these preliminary analyses were found satisfactory, further complexities were introduced by adding groundwater and finally the ubiquitous joints. Groundwater pressures were incorporated from the groundwater flow model. Pore pressures were interpolated at 3DEC grid point node locations for input to the cases that included the effects of groundwater. Coupled analyses were not conducted due to time constraints. Instead, the input pore pressures were used to calculate effective stresses, which were then used in the mechanical calculations.

Interpretation of the results mainly involved looking at velocity, displacements and shear strain within the rock mass for several 3D views, and for many sections about the periphery of the mine. The resulting displacement and velocities were interpreted in a similar way to that of slope movement data. Increasing displacements and velocities with coherent vector fields are a good indicator of instability. It should be noted, however, that the velocities reported from the numerical codes are not to be compared directly to the real velocities measured in the field due to the damping and mass scaling laws used to achieve static equilibrium within the formulations. For this work, the calculated velocity in the model was considered the key indicator for stability (or instability with a threshold of $3 \times 10^{-6}$ (metres/time step), and illustrated in Figures 6 and 7 for a selected cross-section.

Referring to the model results in Figure 6, it may be seen that the south wall near section 06 was stable for the strong rock mass, but a failure surface develops in year 2023 (and for future stages) for the weak rock mass case and for models without pore pressures. The slope failure is observed to be more severe, and instability occurs a year earlier in 2021 when pore pressures and ubiquitous joints are added to the model. Velocity fields for the weak model, shown in Figure 7, confirm the rock mass failure mechanism. It should be noted that the slopes were stable when strong rock mass properties were used. The strong models did show wall movements, albeit no clear failure surface could develop. Using a disturbance factor of 0 is also considered to be unrealistic when considering large-scale rock mass analyses. Hence, we judge that the above scenario of the weak rock mass with a potentially unstable region in the south wall to be a possibility, and mitigation strategies are being considered by the mine to mitigate risks accordingly. 


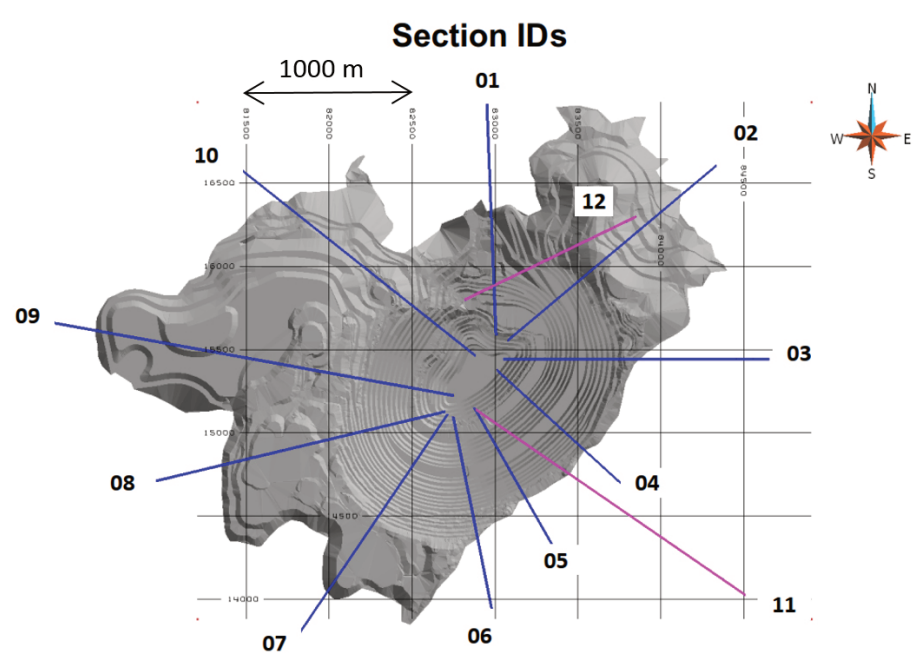

(a)

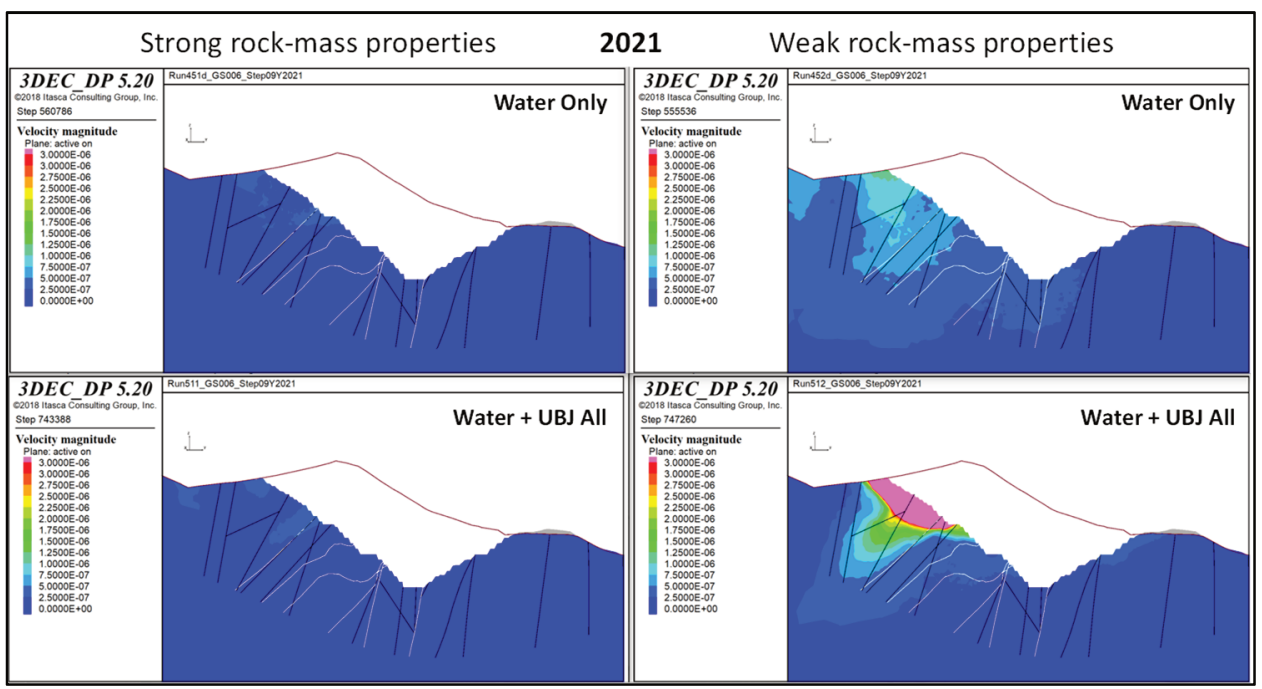

(b)

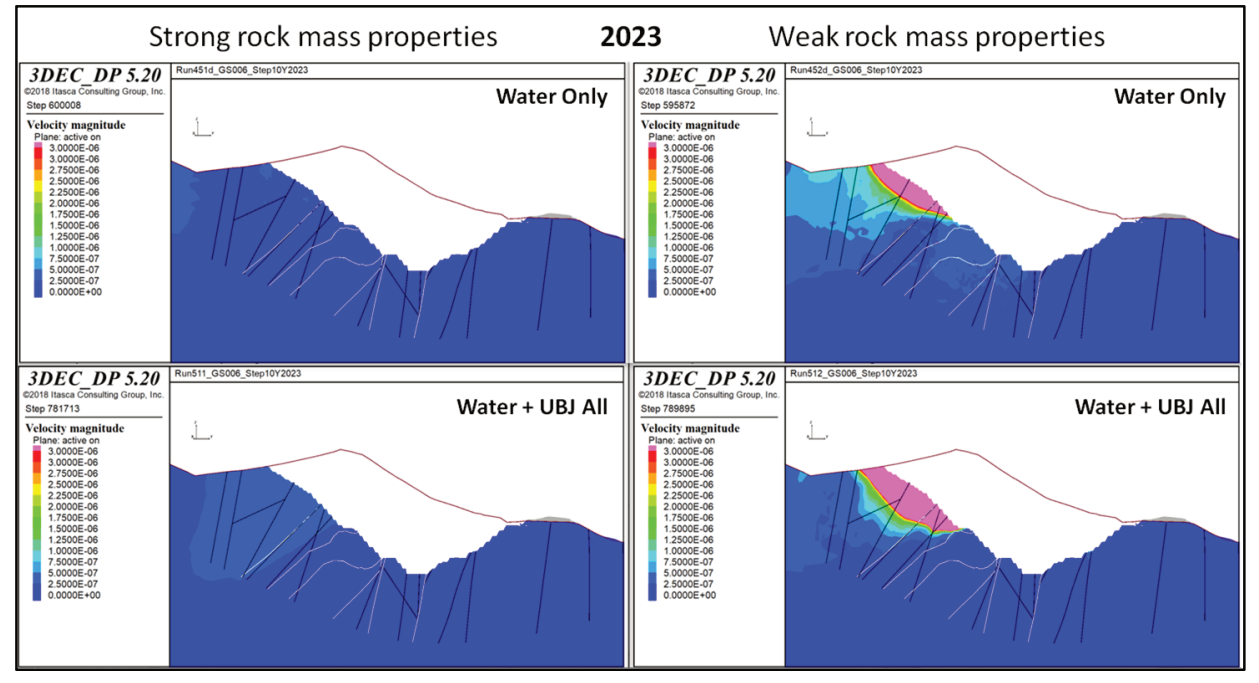

(c)

Figure 6 (a) Location of the plot sections; (b) Calculated velocities on Section 06 for year 2021; and (c) Calculated velocities on Section 06 for year 2023 

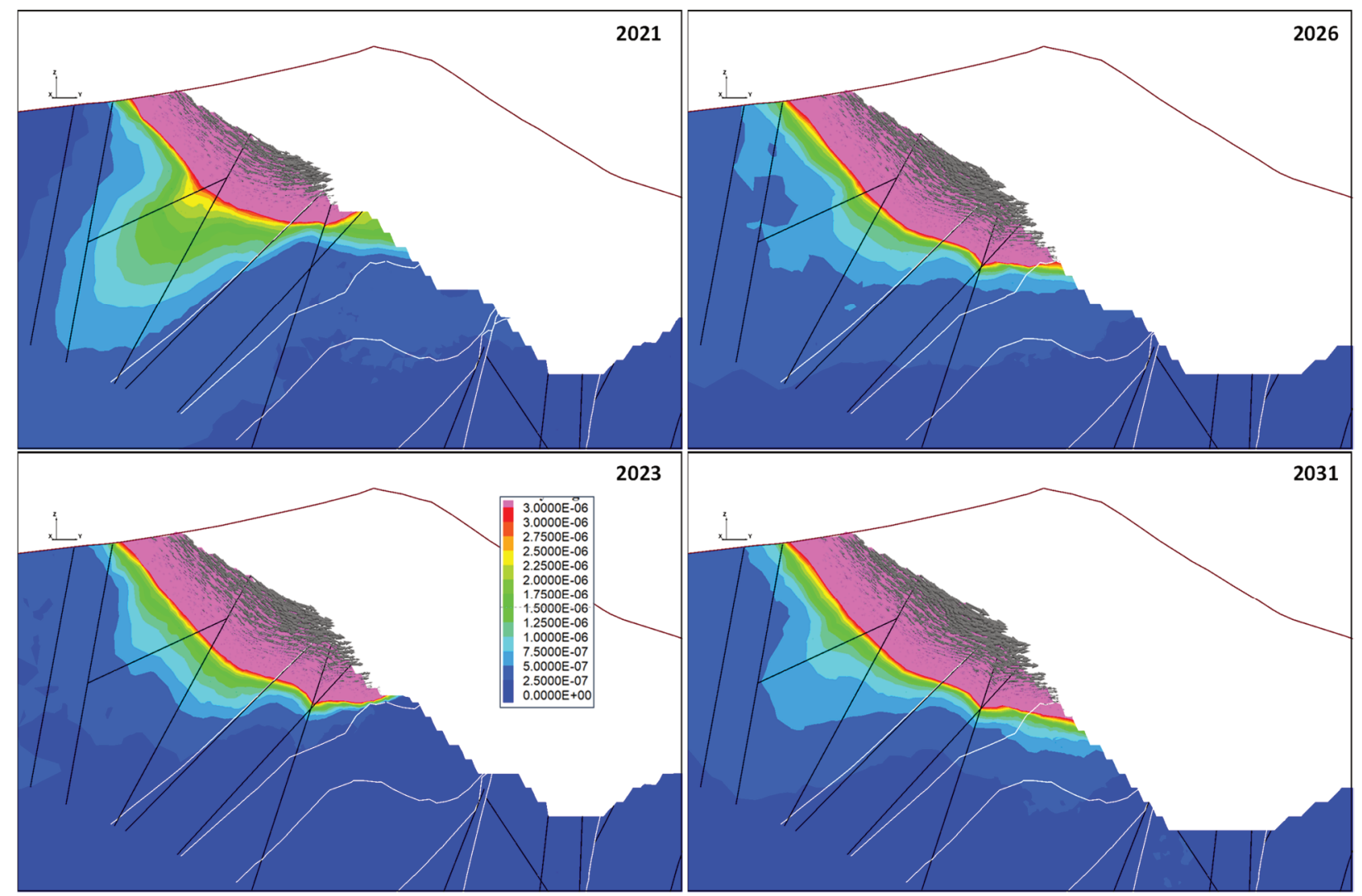

Figure 7 Velocity magnitude and vectors on section 06 for the case of weak rock mass with water pressure and ubiquitous joints included for years 2021 through 2031

\subsection{Detailed 3D modelling of SE deformational event}

A significant deformation event occurred between 2013 and 2015 in the 'wedge' area that forms between the intersection of Ellatsi-1 (E1) and Ellatsi-2 (E2) faults, and this region continues to be a challenge for mine operations. Deformation data from prism measurements were provided by the mine. The analysis of these benchmark data revealed some key months where the velocities/movements were observed to be at their highest (April 2014, April 2015, etc.). The region that moves the most seems to be to the south of the E1 fault (within the Phyllite) but this may be constrained by the prism locations and timing of installation. More recent slope radar data confirm that movements continue in this area.

The results from the mine-scale modelling did not suggest any large wedge movement as a possible mechanism for this region for 2015 to 2031 . Thus, it appears more likely that this deformational event is related to local rock mass degradation. The fact that both E1 and E2 intersect close to the SE wall has likely resulted in a local weakening of the Phyllite and Schist units (Figure 8). Some of the available strength data also indicated low intact rock strength (10-20 MPa) near the faults, but these are inter-bedded with stronger rock fragments (uniaxial compressive strength of up to $60 \mathrm{MPa}$ ). The cell mapping of this region also shows a low rock mass quality; however, it does not reveal any large contrasts within the 'wedge' region, i.e. the values are similar to those of the already weak Phyllite and Schist. A more recent lab testing campaign targeted to this region was undertaken in 2018, revealing some very low intact rock strengths averaging about $6 \mathrm{MPa}$. Based on the examination of the data and visual observations, it was clear that there is a local weakening of the rock mass in the vicinity of E1/E2. It was therefore necessary to devise a modelling strategy to weaken the rock units within a prescribed distance from the E1/E2 faults. It was necessary to reconstruct a new model with more detail and complexity to capture the mechanism(s) of this event (Figures 8 and 9). 


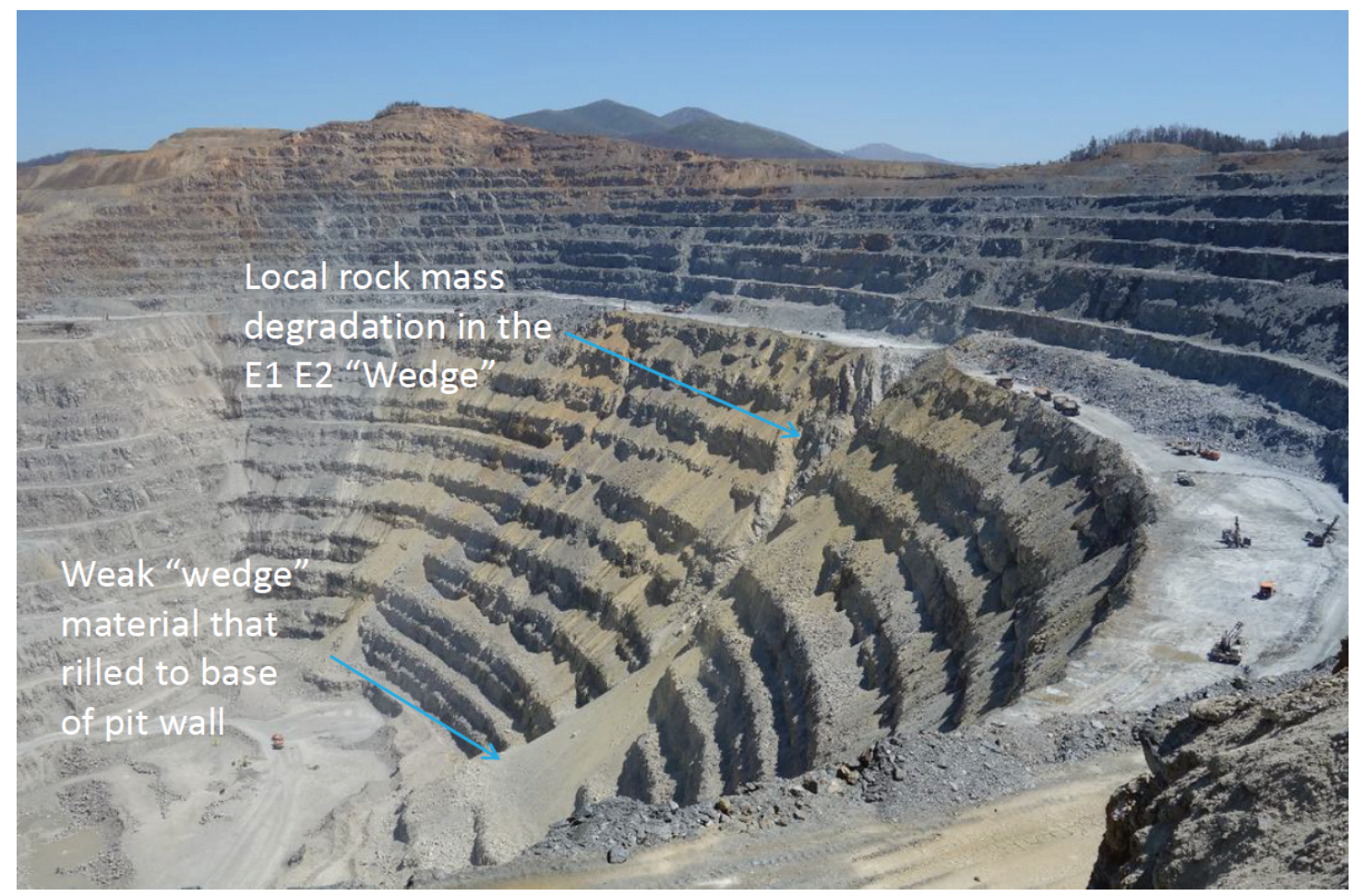

Figure 8 View looking at the region of rock mass degradation related to the SE 'wedge'

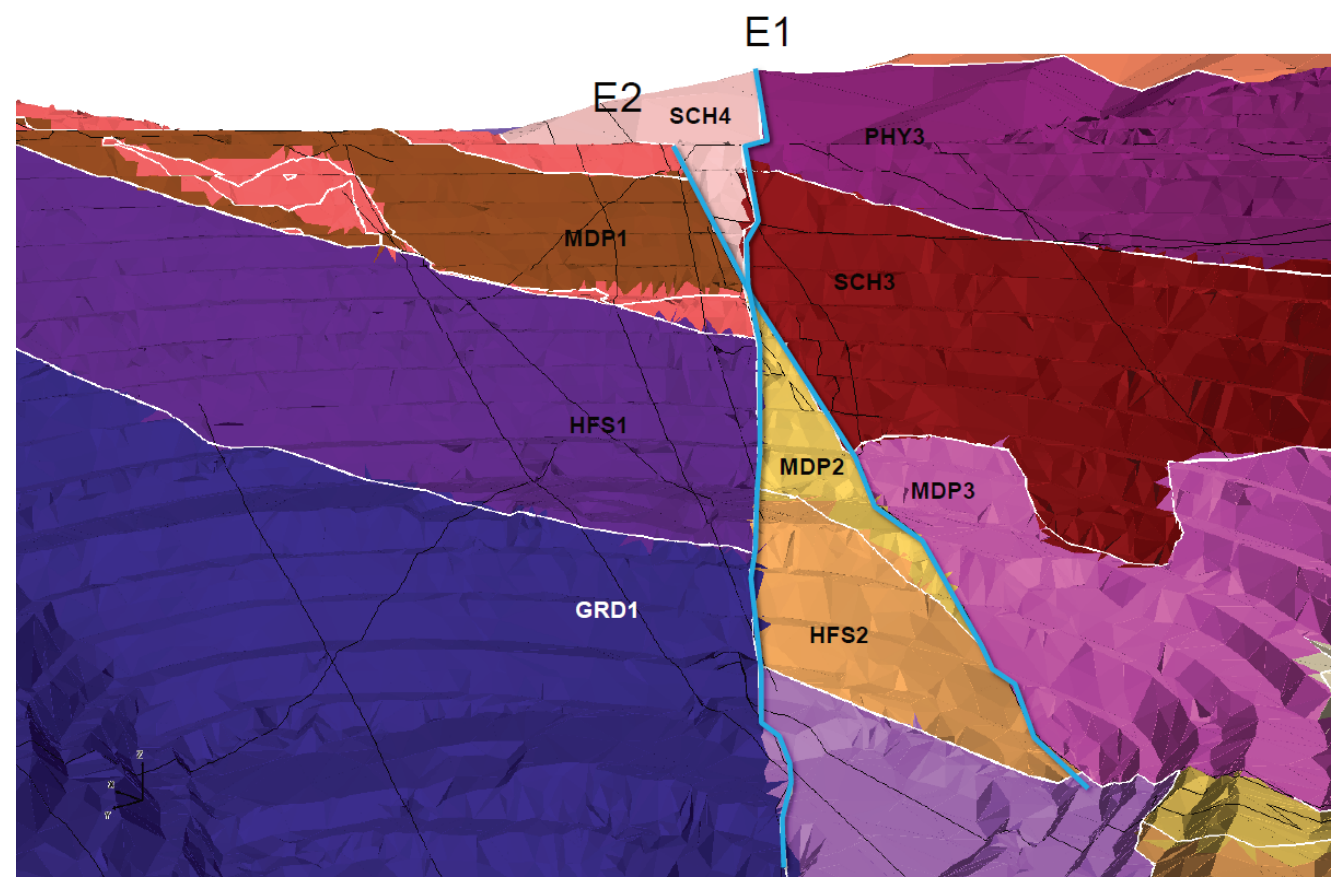

Figure 9 View of 3DEC model of SE deformational event showing the intersection of E1 and E2 and the different lithological units of the model

The main goal was to identify the failure mechanism so that it may be included in subsequent models to evaluate future stability in this area with coming pushbacks, but in the current work only historical behaviour for years 2012 to 2015 were considered. Within the model, the rock units were weakened within a prescribed distance from the E1/E2 faults by reducing the UCS in this region. A $30 \mathrm{~m}$ buffer zone was created, in which the strength was reduced (Figure 10). Two different UCS values were used: 6 and $16 \mathrm{MPa}$ (note that the base case strength for Phyllite is $26 \mathrm{MPa}$ ). The following mining stages were simulated: (i) June 2012, (ii) January 2013, (iii) April 2013, (iv) April 2014, (v) November 2014, (vi) April 2015, and (vii) December 2015. In addition 
to varying the buffer zone strength, models were also run with and without pore pressures (imported from the groundwater flow model).

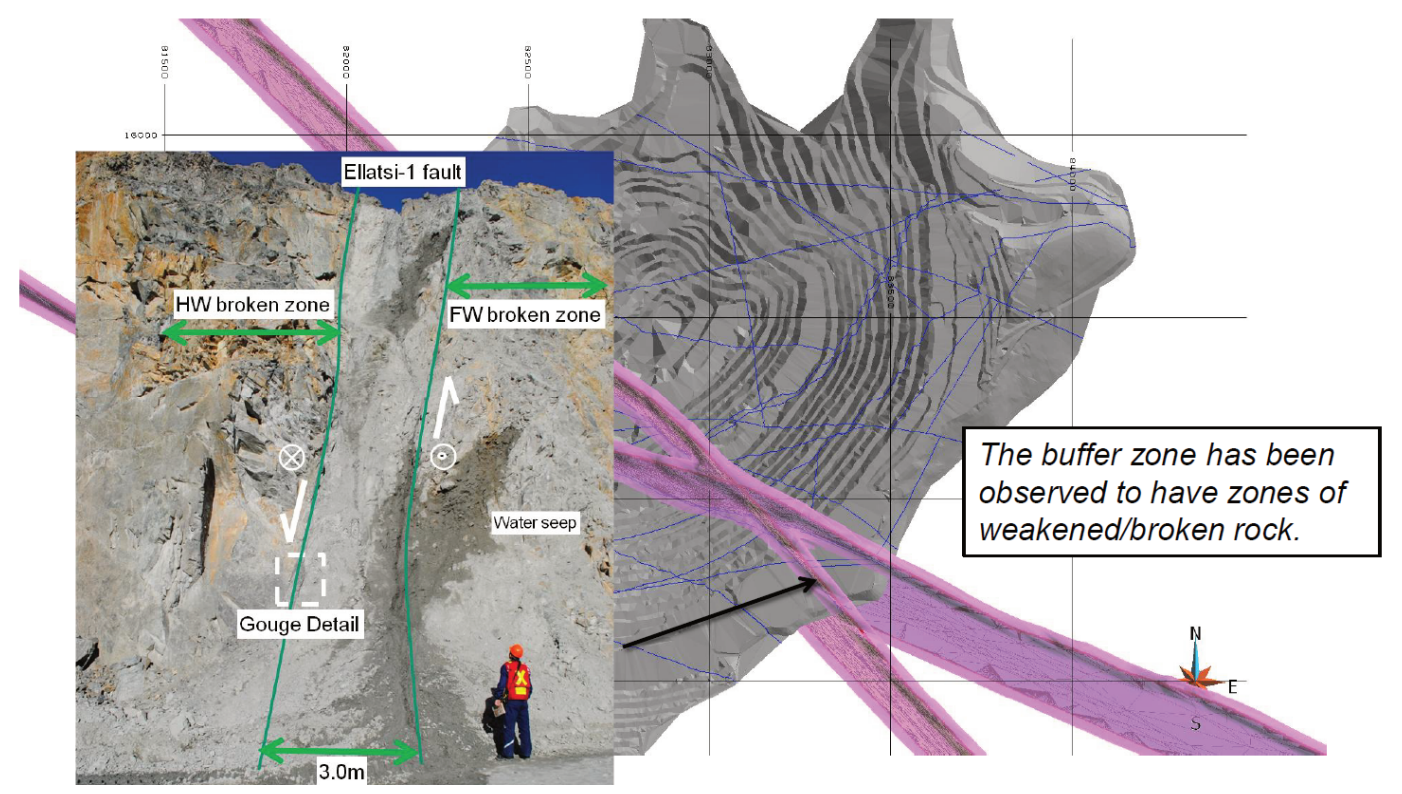

(a)

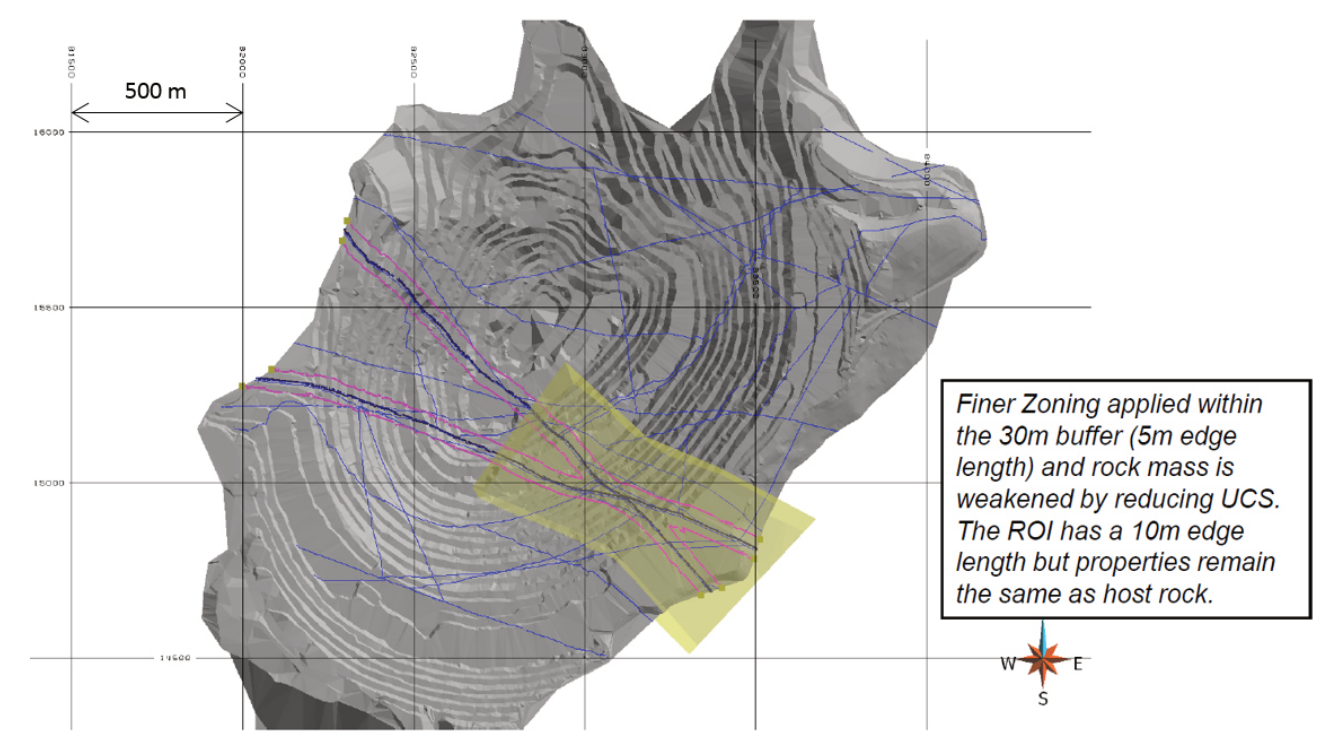

(b)

Figure 10 Key region considered for the SE event. (a) A buffer zone $(30 \mathrm{~m})$ about the faults was created to facilitate strength degradation; (b) A region where finer zoning was applied

The results showed that the models with no weakened buffer zone did not capture the desired response. Limited movements, such as local blocks, were observed but no large-scale instabilities or mechanisms developing. When adding pore pressures, movements increased in magnitude, but no major instabilities developed in the model for the case with no weakened buffer zone. For the next case, with a weakened buffer zone with the $6 \mathrm{MPa}$ UCS value, the model generated a response in the region that is similar to observed behaviours, as exemplified in Figure 11. The mechanism appears to be well captured using this approach and the model did agree qualitatively well with benchmark prism data. This model was run without pore pressure and when adding pore pressures movements would be too large compared to observations. It can thus be concluded that this model is likely too weak. 
For the case with the $16 \mathrm{MPa}$ UCS value for the buffer zone, the overall trends and behaviour are similar to the weaker-strength case, but displacements are lower (Figure 12). The failure surface is shallower, which may be a better reflection of site conditions, although field data supporting the failure depth are not available. When adding pore pressures for the model with the $16 \mathrm{MPa}$ buffer zone, a broader region of movement with higher displacement values was observed, yet markedly less than for the $6 \mathrm{MPa}$ buffer zone with pore pressures added. Hence, this case is considered a more realistic representation of actual conditions.

Both observations in the pit, as well as a recent laboratory testing campaign, indicate that the rock material adjacent to E1 and E2 is weaker than the original host rock. The presented modelling results, with a $30 \mathrm{~m}$ buffer zone of weakened material, further show that the weak transitional zones adjacent to the E1 and E2 faults are likely major contributors to the deformational event of the SE wall. Kinematics alone, with blocks moving, is not enough to explain the observed behaviour. Some additional fine-tuning of parameter values may still be required for a more quantitative match with monitoring data.

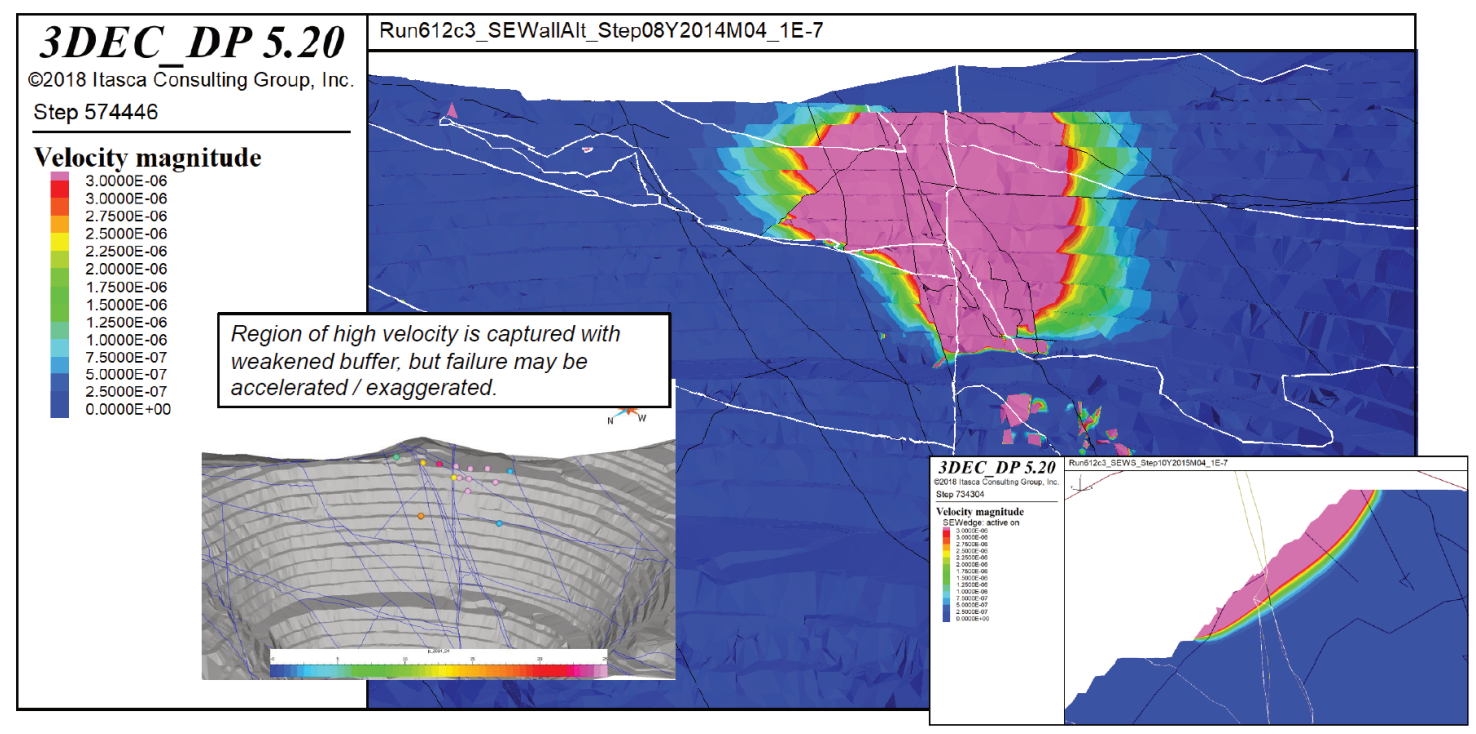

Figure 11 Calculated velocities for the case with UCS = $6 \mathrm{MPa}$ and mining corresponding to April 2014 with insets showing benchmark movement data (left) and section through the unstable volume (right); same scale and legend for velocities in both figures

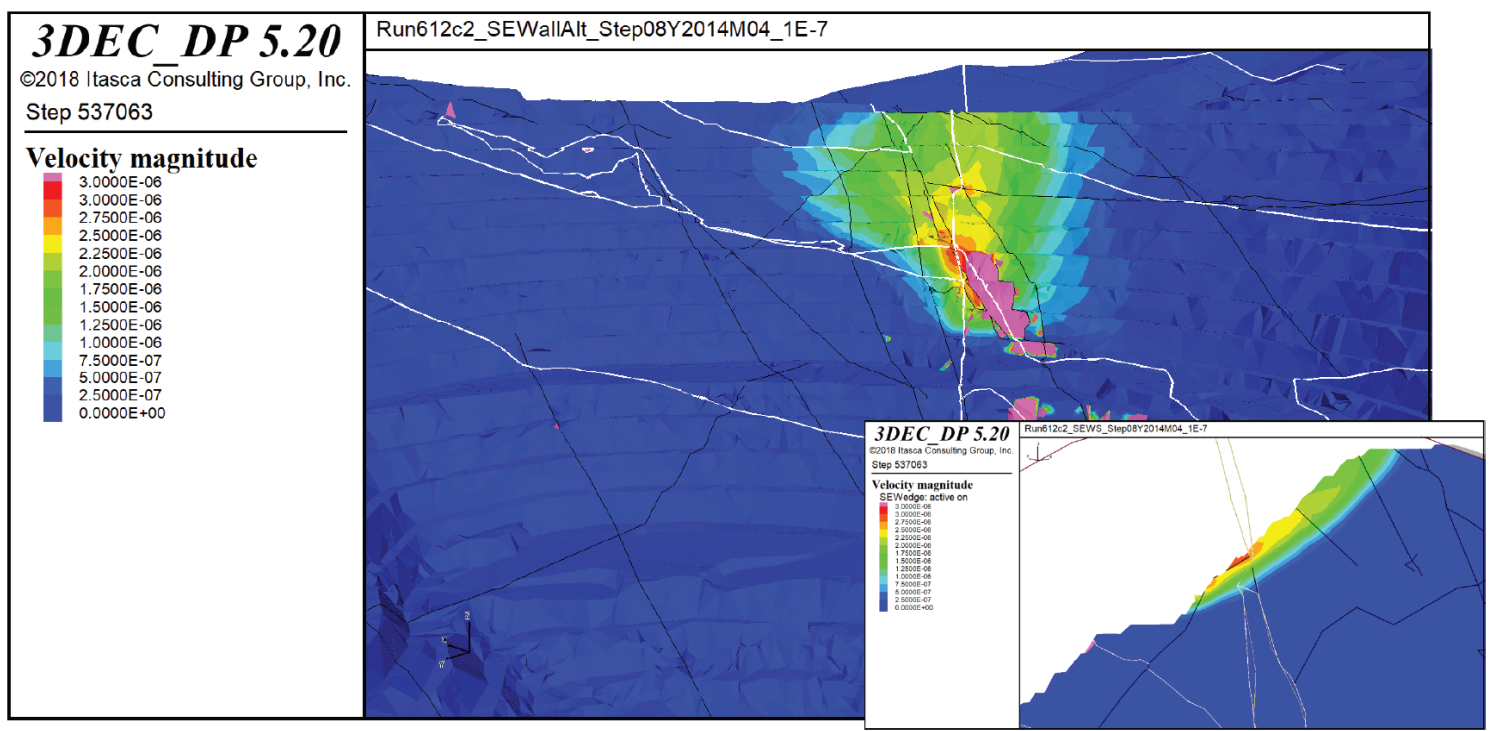

Figure 12 Calculated velocities for the case with UCS = $16 \mathrm{MPa}$ and mining corresponding to April 2014; same scale and legend for velocities in both figures 


\section{$5 \quad$ Remedial measures and recommendations}

The work presented above has shown both the potential for a large failure region in the south wall for future mining, as well as larger local wall movements in the E1/E2 fault intersection in the southeast wall. Multiple mitigation techniques will be needed to manage these risks. It seems clear that the weakened buffer zone dictates the failure in the SE region. It is anticipated that when mining progresses past the weakened buffer zone, slope conditions will improve. In order to manage this risk, more work on delineating the weak zone is required, specifically the transition to higher strength rocks. This may be achieved through supplementary core drilling, point load testing, and laboratory testing. Extending a dewatering program to this region would likely also help. However, this region may also continue to degrade under dry conditions if the rock is weak.

For the potential large failure region in the weak Phyllite and Schist units, mitigating measures may include maintaining geotechnical push backs as well as implementing a dewatering program. The groundwater flow model was employed for forward modelling to predict pore pressures and phreatic surface locations and as input to the design of a conceptual dewatering program. The south area of the pit, dominated by the Phyllites, was selected as the main target area. Potential slip surfaces output from the geomechanical modelling described above were used to target dewatering. A nearly north-south striking vertical cross-section was chosen to present the pore pressure distributions at different mine stages (Figure 13).

A conceptual dewatering program was designed, incorporating seven levels of sub-horizontal drainholes with lengths of 220 to $250 \mathrm{~m}$ in the area of potential slope failure, cf. Figure 13. Sub-horizontal drainholes were selected over vertical dewatering wells or drainage galleries because they are easier to implement, are more effective than vertical wells in reducing pore pressures, and are less expensive than wells or drainage galleries. Forward modelling including these drainholes confirmed that after implementation of the conceptual dewatering program, the phreatic surface within the Phyllites in the southern portion of the Mine would meet the slope stability objective. An example for year 2031 is shown in Figure 14.

Before implementing a full-scale dewatering/depressurisation system, the effectiveness of sub-horizontal drains can be assessed through the installation of piezometers that are located near the drainholes. The location of the phreatic surface for current conditions should be also be verified prior to implementing a dewatering/depressurisation system. It is recommended that piezometers be located in at least two to three locations along cross-section B-B'. Each piezometer can be integrated within an inclinometer to obtain information regarding potential slip surfaces along with water levels.
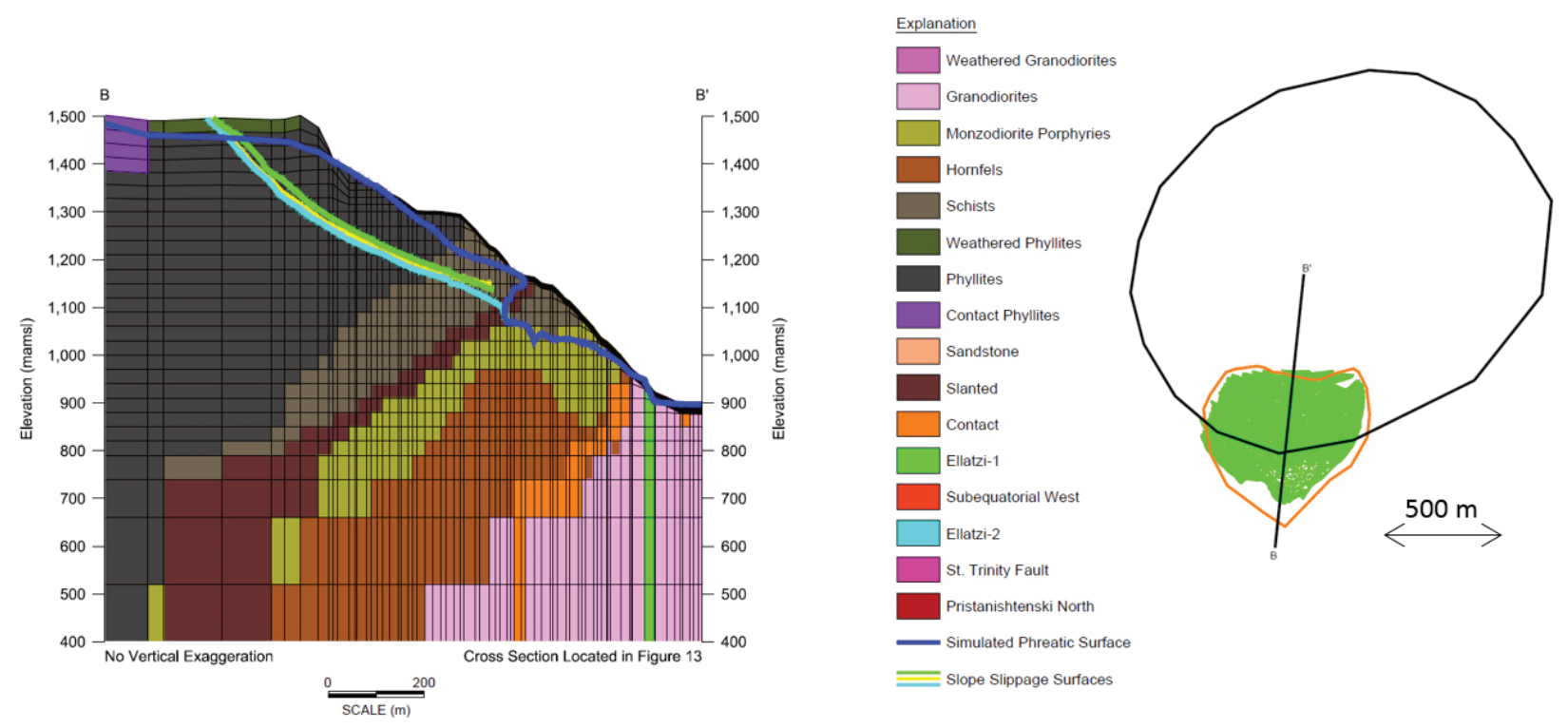

Figure 13 Vertical cross-section B-B' showing the phreatic surface location as of December 2019 (cross-section location shown to the right) 

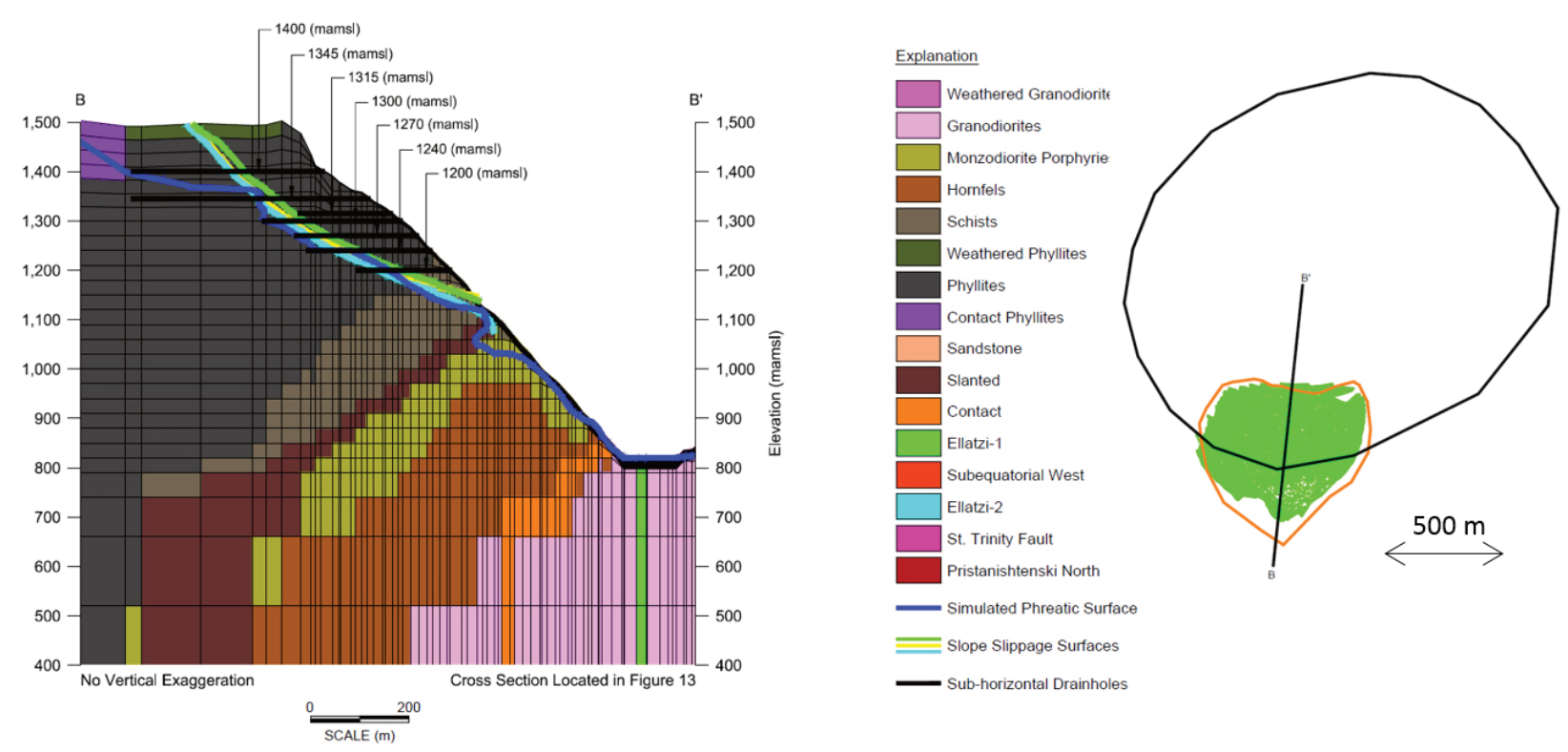

Figure 14 Vertical cross-section B-B' showing proposed drainholes and predicted phreatic surface location as of December 2031 (cross-section location shown to the right)

\section{Concluding remarks and recommendations}

The challenging slope stability conditions at the Ellatzite mine have been tackled through an integrated geomechanical and hydrogeological approach. The developed GFM incorporates all six main lithological units and 20 separate structural-litho units, 59 faults and all laboratory and characterisation data collected at the site. The GFM is judged to be representative in describing the geomechanical context of the site. The use of the GFM approach for Ellatzite has enhanced understanding of the host geological/geomechanical/ hydrogeological environments and provided an invaluable communication tool between sub-disciplines.

The groundwater flow model has been shown to reasonably simulate the past and current hydrogeological conditions at the mine, with acceptable transient calibrations to the available data being achieved. Thus, the model was sufficient to conduct various dewatering/depressurisation simulations for future mining, to develop a conceptual dewatering program and to generate pore pressures through time as input to geomechanical modelling. For future improvements of calibration, more local faults may have to be included to obtain a better match between the measured and simulated water levels in some of the monitoring wells.

The detailed mine-scale 3DEC model includes all geological and structural features and has pushed the boundaries as to what is possible to achieve with the continuous development of numerical modelling codes. The model enabled investigating the importance of various factors affecting the large-scale stability of the pit slopes. The model results provided early warning of a potential large unstable volume in the south wall for future mining stages. More detailed analysis of the E1/E2 fault intersection confirmed that slope deformations are likely due to weakening of the rock mass near the faults.

Based on these findings, the following recommendations for future work are given:

- A geotechnical berm should be considered for the south pit wall to help mitigate identified stability risk in this area.

- A dewatering program should be implemented in the south wall to reduce pore pressures and thus reduce the risk for large-scale slope instabilities. A pilot study should be implemented to assess the effectiveness of sub-horizontal drainholes, involving installing strategically located piezometers prior to the drilling of the sub-horizontal drainholes.

- Additional efforts to delineate the weak buffer zone surrounding E1 and E2 need to be made. 
- Reconfiguration of the slope geometry and dewatering (to lower pore pressures) both need to be considered to deal with the E1/E2 fault intersection zone.

- Additional multi-level piezometers and piezometers/inclinometers should be installed near or within the pit slope, especially in the area of the estimated slope instability.

Several of the above recommendations are already being considered and actions are being taken by Ellatzite-Med AD. Initial implementation includes geotechnical drilling near the E1/E2 intersection zone as well as planning for a dewatering program.

\section{Acknowledgement}

This work has been funded by Ellatzite-Med $A D$, which is gratefully acknowledged. We would also like to thank the management at Ellatzite-Med AD for permission to publish this work. The support from staff at the site has been instrumental in obtaining and compiling representative data for slope stability assessment, and we are grateful for the support and good cooperation provided by the mine staff.

\section{References}

Azrag, E, Ugorets, VI \& Atkinson, LC 1998, 'Use of a finite element code to model complex mine water problems', Proceedings of Symposium on Mine Water and Environmental Impacts, International Mine Water Association, Johannesburg.

Bieniawski, ZT 1989, Engineering Rock Mass Classifications: A Complete Manual for Engineers and Geologists in Mining, Civil, and Petroleum Engineering, John Wiley \& Sons, Hoboken.

Hoek, E, Kaiser, PK \& Bawden, WF 1995, Support of Underground Excavations in Hard Rock, A.A. Balkema, Rotterdam.

Hoek E, Carranza-Torres, C \& Corkum, B 2002, 'Hoek-Brown failure criterion - 2002 edition', Proceedings of the 5th North American Rock Mechanics Symposium and the 17th Tunnelling Association of Canada Conference, University of Toronto, Toronto, pp. 267-273.

Itasca Consulting Group, Inc. 2018a, 3DEC, version 5.20, computer software, Itasca Consulting Group, Inc., Minneapolis.

Itasca Consulting Group, Inc. 2018b, Griddle, version 1.0, computer software, Itasca Consulting Group, Inc., Minneapolis.

Laubscher, DH 1990, 'A geomechanics classification system for the rating of rock mass in mine design', Journal of the South African Institute of Mining and Metallurgy, vol. 90, no. 10, pp. 257-273.

Marinos, P \& Hoek, E 2000, 'GSI: a geologically friendly tool for rock mass strength estimation', Proceedings of the International Conference on Geotechnical \& Geological Engineering, Melbourne, pp. 1422-1442. 
Advanced three-dimensional geomechanical and hydrogeological

L Cotesta et al. modelling for a deep open pit 